\title{
An Anthropology of Welfare: Journeying towards the Good Life
}

\author{
Susanne Langer and Susanne Højlund
}

This issue of Anthropology in Action is dedicated to the study of welfare - understood as a social, culturally specific and long-term process of transformation - from an anthropological perspective. But is a study of 'welfare' still relevant and is it an appropriate concept to study what counts as a 'good life' well-lived? Has comprehensive publicly funded welfare still a role to play, or have collective welfare arrangements and institutions not been replaced by individuals' personal quests for well-being?

Certainly, there has been a remarkable shift away from the social, political, historical and economic conditions and discourses that underpinned the classic post-war welfare states. For instance, in the U.K., recent decades have seen attempts at re-designating citizens as consumers who demand choice, and economistic rhetoric and financial accounting are now as much part of the public sector as of the private sector. The state and the private sector have become intertwined in myriad new ways, through subcontracting, outsourcing and novel finance and ownership arrangements. There has also been an increasing rhetorical emphasis on the need for individuals to show greater evidence of initiative and independence, a development that has gone hand in hand with a reconfiguring of the state from provider to enabler. While it is important to pay attention to the specific contexts in which these changes are taking place in the U.K., they resonate with debates and developments in other western European countries. The imperative of participation in the paid labour market as the norm and on 'active' citizens is evident not only in the U.K. but also in Denmark and in Germany's recent reforms of the system of unemployment benefits.

Hence the question arises of how it is possible to study welfare in these changed conditions. For anthropologists with their global perspective, further questions open up, including how we can speak of welfare in the contexts of lives shaped by a relative absence of the state.

To us, these developments point to a need to approach welfare not as a static or monolithic concept but instead as a set of shifting and diverse practices of disparate agents that include individuals, communities and organisations. An emphasis on practices allows the study of diversity in the pursuit and definition of the 'good life', as well as offering an opening into how welfare practices can become the embodiment of particular forms of ethical orientations and normative expectations. We draw inspiration for this approach from Ingold's work on the relationship of movement to lines (Ingold 2007).

\section{Lines, Movement and Faring Well}

For Ingold 'lines' are not only ubiquitous in nature but also central to culture. He makes a key distinction between what he calls the 'fragmented' and the 'continuous' line and associates them with different modes of movement. The fragmented line serves to link together a series of distinct dots and is associated with movement as 'transport'. For Ingold, transport 
is constituted by moving from one location to the next in a way that pays little attention to the sights and experience encountered in transit and that leaves the travellers unaffected. In contrast, the movement of the continuous line is more akin to what he terms 'wayfaring', a 'development along the line of life' that changes the very being of the wayfarer (Ingold 2007: 77, original emphasis). This is not a one-way process as wayfarer and environment are shaped mutually and concurrently. Illustrating his distinction with examples from hunter-gatherer and nomadic cultures, Ingold emphasises that wayfaring is not directionless or restricted to a particular mode of transport, and while wayfaring may leave few discernable traces, it is 'neither placeless or place-bound but placemaking' (Ingold 2007: 101, original emphasis). Hence, for Ingold wayfaring is a practice of observation of and engagement with the environment along a line of movement. While, in our view there is a danger of overstating the difference between wayfaring and transport - after all, road-rage and travel sickness leave few travellers unchanged - Ingold's original meditation on the universality of lines proved inspiring. What if, we asked, 'welfare' is not seen as a measurable objective state, but instead as daily practice and ethical orientation? In other words, what if we begin to speak of faring well through life, or of 'well-faring', in a sense that is analogous to Ingold's 'wayfaring'?

There are a number of considerations why we take Ingold's notion of 'wayfaring' as the starting point for an anthropological exploration of 'well-faring'. First, faring well is rarely an enduring state and frequently remains transitory or elusive. Second, often an element of mobility is required in order to pursue and achieve it. Third, movement is also evident in the future-orientation of many well-faring practices, either through inter-generational cooperation or through the changes brought on by a person's progression through life. Furthermore, welfare as a form of collective assistance is most keenly needed in periods of major tran- sitions, such as during education, illness, or unemployment. Faring well, like wayfaring, does not begin with a blank slate but proceeds through constant engagement with and movement through an environment that is both naturally and culturally shaped. It always implies a definition of what is and what should be, about different kinds of agents and about rights and obligations. Faring well is therefore both pragmatic and moral. Furthermore, despite its diverging specifics, the desire to fare well through life is universal, although aspirations and opportunities are not evenly matched nor is such a desire necessarily beneficial to everyone or altruistic. This also applies to groups because well-faring is not merely a personal endeavour but is culturally specific and as such it is collective too. This is evident in the ways that families, kin groups and communities across generations aim to ensure that they prosper in the present and in the future. The four articles assembled in this issue serve to illustrate the characteristics of well-faring outlined here.

\section{A Cultural Turn in the Study of Welfare?}

At present the study of welfare is largely the domain of social policy specialists and economists, but interest in alternative approaches to the study of welfare has been growing. Clarke (2004), for instance, has called for a 'cultural turn' in social policy and welfare studies, Appadurai (2004) has collaborated with World Bank economists to highlight the importance of hope or what he terms the 'capacity to aspire' in the creation of well-being, while the Danish Forskningsrådet for Kultur and Kommunikation (Research Council for Culture and Communication) (2007) has called for a study of welfare that is able to look 'behind the figures'. Such developments outside anthropology meet with a long-standing and recently resurgent interest in welfare and well-being within the field. 
The pioneers in this respect have been Edgar and Russell, who situate their edited volume, The Anthropology of Welfare, within the discipline's 'strong tradition of representing the minority, the underdog, the dependent, and disempowered' (Edgar and Russell 1998: 1). In so doing they located the study of welfare within a well-developed tradition of anthropologists speaking 'for' those who cannot speak for themselves, a position that also integrated well with the basic premises of social work, community care and therapeutic interventions, which were all areas covered by the book's contributors. The book's geographical parameters were established by field-sites located in the U.K., Sweden, Portugal, the U.S. and New Zealand, all of which have been described as 'welfare states', albeit of different types (Esping-Andersen 1990). While the book opened new doors for the anthropological study of welfare, it has also been hampered by a conventional interpretation of what constitutes welfare. Restricting 'welfare' as concerning only those 'in need' defines it in particularistic rather than universal terms and stresses its potential to divide and stigmatise rather than to redistribute and enable. Furthermore, even before the publication of The Anthropology of Welfare the discipline's claim to speak 'for' others had come under serious critique, not only within the field but especially from those people to whom anthropologists aimed to give voice. The growing presence, impact and acceptance of self-help and service user groups, tenant associations, organisations of disabled people, as well as a wide range of civil-rights movements suggests that anthropologists' role today may be more that of facilitator and mediator. Similar shifts have occurred within the caring and therapeutic professions, with even traditional biomedicine laying claim to a more 'patient-centred' approach than practised in the past.

The book's focus on traditional welfare states is explained by these being the sites where 'welfare anthropologists' have worked (Edgar and Russell 1998: 3), yet it also risks losing anthropology's expertise in non-western settings. That such locations require a different approach has long been recognised by Keebet and Franz von Benda-Beckmann (Benda-Beckmann et al. 1988). They developed the concept of social security as a way to study strategies of coping with insecurity in developing world context where notions of state-based welfare systems would be inappropriate. In their interpretation, social security encompasses the study of both kinship and communities, as well as of state bureaucracies and other more formal layers of social organisation, and focuses on the actors, processes, institutions and interests involved in its creation. Although originating in the anthropology of development, the concept of social security has been fruitfully applied to traditional welfare states and most recently to the former socialist states of Eastern Europe.

By combining the concept of social security with feminist approaches to care, Read and Thelen (2007) offered an innovative view on welfare and the public and private provision of care in former socialist states. In particular they employ this approach to challenge the widely held view that the end of socialism was equated with a withdrawal of the state from public welfare provision. Read and Thelen acknowledge that everyday social security and care arrangements in socialist countries have been fundamentally altered since 1989 - a change that is frequently experienced as a form of 'loss' - but warn against interpreting this as 'withdrawal'. Doing so would represent a rather one-dimensional view of 'the state' as a singular entity with clearly defined boundaries, which in turn would make it difficult to understand the complex and contradictory nature of reforms in former socialist countries and to recognise the diverse range of state bodies, actors and institutions that continue to shape social life in the region. Instead they point out that although in post-socialism the rationale for welfare has changed from uni- 
versal to targeted - as have in many cases the providers, with churches, charities and other NGOs replacing the state - the state nevertheless continues to 'regulate, mediate, and/ or finance these services' (Read and Thelen 2007: 10). Secondly, they suggest that the 'state withdrawal' model closes rather than opens up avenues of enquiry and offers little analytical purchase on the reconfigurations of public and private spaces, moralities and subjectivities that have taken place. They exemplify their point with the case of 'privatization' which in former socialist countries took multitudinous forms, with formerly private spaces, practices, subjectivities and networks being incorporated into new socioeconomic realities, including forming the basis for new public 'non-state' enterprises.

Read and Thelen's reminder that the state remains a major force in the provision of welfare even under circumstances that are conventionally interpreted as a withdrawal of the state supports our view that welfare is still an appropriate shorthand to refer to the diverse practices of maintenance and care that characterise it. However, we prefer welfare over the more recent well-being also for its association with long-term collective action and with politics. As charted by Sointu (2005), despite being originally used to discuss the functioning of the state and in relation to wider social structures, well-being has become associated with 'women's issues' and personal, relatively easy, and generally pleasurable activities that were uncritically conceptualised as 'being good' for the person. Well-being practices have become increasingly commercialised and mainstreamed to lend them greater consumer appeal, illustrating for Sointu a shift of meaning from the 'body politic' to the 'body personal'.

Nonetheless terminology remains a sensitive issue as James (2008) has demonstrated and as the titles of two recent anthologies dedicated to the anthropology of well-being show (Corsín Jiménez 2008; Mathews and Izquierdo 2009). For James 'welfare' and 'well-being' pos- sess different connotations. While the former can only be imagined, she writes, in the context of a larger social whole, it is 'awkward to try to apply the latter to interests outside the immediate life of individual persons and their close circle' (James 2008: 76). Yet, well-being's focus has lent it new credence in the currently predominant discourse of liberal politics and economics and has imbued it with the potential to describe activities that would previously have been considered welfare work. While such linguistic 'sleight of hands' makes the lack of provision for 'truly fundamental social needs' nearly invisible it also has allowed for the provision of aid that has been closer to traditional notions of welfare (ibid., original emphasis). James grounds her argument in the activities of NGOs providing aid to Sudanese refugees in Ethiopia. Interestingly, however, she also points out the continued importance of governments in the provision of such aid and insightfully demonstrates the limitations of the language of 'well-being' in the longer term, because individual well-being is inextricably bound up with collective concerns, such as in her example the demographic survival of the ethnic group in question and the eventual return to their original homelands and way of life, which both are questions that can only be addressed by political means. In addition to Ingold's concept of wayfaring, it is James' reminder that being well is a social and political project that underpins our decision to use the term 'welfare' rather than 'well-being', a term that while not without ethical charge and potential for collective change, is still predominantly used in a depoliticised and individualised way. In so doing we differ from the authors of two edited collections that are indicative of anthropologists' continued and current interest in well-being and welfare (Corsín Jiménez 2008; Mathews and Izquierdo 2009). In addition these two collections demonstrate the range of approaches and diversity of ideas in the field. While Mathews and Izquierdo's edited volume asks what it takes to be 'happy' 
in different cultures, Corsín Jiménez' is more concerned with the analytical and philosophical purchase of the concept of 'well-being'.

Mathews and Izquierdo's approach can be described as traditionally anthropological. Focusing their attention on well-being defined as 'an optimal state for an individual, community, society, and the world as a whole', they explore what it means to live 'well' in different cultures but they are also in search of the fundamental human universals of well-being (Mathews and Izquierdo 2009: 5). The book is divided into four sections: a theory section, a section on notions of well-being in small-scale societies, one on well-being in large-scale societies, and a final one that considers physical pleasures, the subjective experience of the 'self-scape', and the efforts of families with children with disabilities to create routines. The first theory paper by Thin (2009), is a forceful critique of anthropology's disregard of well-being, happiness and normality, and a spirited argument of the imperative of a study of well-being to anthropology while the second paper in this section aims to present a theory of well-being that links a theory of culture as 'self-world' with biology (Colby 2009). The ethnographic chapters introduce different notions of well-being each situated in particular environments, practices and forms of social organisation. The studies of large-scale societies demonstrate that happiness is rooted in different socio-centric orientations - either as subsuming individual desires into the wider concerns, developing niches to exercise one's individuality, or striking a balance between these poles.

In contrast to Mathews and Izquierdo who are concerned with well-being and happiness across different cultures, Corsín Jiménez uses his publication to argue for persons as the measure of well-being, and to propose 'proportional sociality' - understood as a combination of social analysis and a theory of ethics - as a tool for its study. He uses the concept of proportionality to alleviate what he considers the respective failings of economists and anthropologists, the first preferring working with wholes, while the latter focus their attention on relationships at the expense of wholes, including societies. Proportional sociality, for Corsín Jiménez, then elucidates the factors by which persons extend their biographical projects and it concerns agency and the means and resources necessary to modify the relationships that make up persons. This focus on extension situates well-being in the context of personhood and opens up the questions of where well-being is located and what its size is. Thus the social becomes the personal or, in the words of Corsín Jiménez: 'Persons are social life writ small, expressed in the emerging forms of proportional (that is biographical) sociality' (Corsín Jiménez 2008: 194). Having established how the concept of proportional sociality can change anthropological approaches to the study of well-being he then identifies how it can already be identified in the work of moral philosophers and economists who have tried to estimate well-being, tracing the presence of social proportionality through the concepts of aggregation, distribution and proportions and the work of Aristotle, Plato, Hobbes and Derrida.

While Corsín Jiménez' argument for proportional sociality at the centre of an anthropology of well-being will certainly raise accusations of relativism, we welcome his project for taking the person, understood as the extension of their relationships rather than as merely synonymous with the Euro-American individual, as the measure of well-being. In particular we recognise his notion of the person as the expression of social life as an opportunity to understand the changing nature of the neoliberal nation-state, from one dominated by its bureaucracy to one that is constituted by an entanglement of public, private, voluntary actors. We also welcome Corsín Jiménez' insight that well-being is always less than perfect, and that falling short of hopes and expectations lends social life, expressed through persons' biographical projects, its dynamic tensions 
and uncertain outcomes. We want to pick up on this in our focus on well-faring. However, and contrary to Corsín Jiménez, we are less interested in the theoretical implications of such oscillations, and more in people's actual movement in terms of their social and material environments and across the life course.

\section{Welfare as Practice and Movement}

Of the contributions making up this issue, the aspect of movement is most clearly developed in the article by Hall and Smith, who are explicitly concerned with the mobile practices of urban welfare, care and upkeep. They accompany three very different well-farers on their walks through the changing urban landscape of the Welsh capital, Cardiff: Billy, a homeless man, Jeff and Charlie, two outreach social workers, and Steve of Cardiff's city centre management team. The three walks are inextricably linked with the city' transformation from a place of production to one primed for the demands of the knowledge economy and the service industry, especially retail and tourism. As Hall and Smith make clear, Cardiff City Council has explicitly premised its investments on creating a city with an outstanding 'quality of life'. Central to their strategy has been to prioritise the movements of pedestrians in the city centre in an attempt to invite passersby, commuters, tourists and shoppers to linger rather than simply use the city streets and spaces as thoroughfares on their journeys elsewhere. As the authors point out, this intentional approach to the environment is the opposite of Ingold's understanding of wayfaring as creating the path by walking. Rather, in the case of Cardiff, changes in the physical environment of the urban landscape were intended to precipitate the hoped for arrival of affluent visitors, enlivening the newly created urban landscape in ways that are often depicted as generative of insurmountable conflicts between commerce and communities.
However, the authors choose not to present their ethnography in this way. Rather, they highlight the numerous, criss-crossing pathways of well-farers in the urban landscape and the multiple and often contradictory practices of maintenance, upkeep and care in which they engage in pursuit of the good city and ultimately the good life.

The following two articles focus on major transitions across the life course, rather than on physical movement. Gulløv turns her attention to early years child-care in Denmark, before de Jong discusses the complex intergenerational preparations that South Indian Muslims undertake in order to secure a 'good' old age. The two articles exemplify the considerable scope of an anthropology of welfare, in terms of field-sites, age groups and ethnicity, yet they also serve to identify a unifying feature of such a project not only by focusing on the life course but by highlighting the culturally specific notions and practices that shape trajectories of well-faring.

In her article, Gulløv skilfully weaves together the macro level in the shape of the challenges of the globalised economy, immigration and the future of the welfare state, with the micro level as evident in the attitudes and practices of everyday child-care of parents and of child-care professionals. For Gulløv child-care constitutes in Collier and Lakoff's (2005) terms 'a regime for living', that is, a configuration of normative, technical and political elements that are evoked in the face of ethical dilemmas. In recent years, Denmark has experienced an unequalled expansion of early years day-care provision, with the vast majority of children attending day-care institutions from one year onwards. The near universality of institutional child-care in Denmark has increased the public standing of child-care professions, and makes considerable demands on the resources of Danish municipalities. Within child-care institutions it has also led to considerable strains caused by the daily work of looking after sub- 
stantial numbers of often very small children with a limited number of staff. Hence, normative values and cultural expectations, such as independence, cooperation and a preference for the verbal resolution of conflicts are reinforced by the day-to-day demands of running a child-care centre. Gulløv's article centres on the struggles of three-year-old Ibrahim, his parents and his child-care professionals. While his parents emphasise his need for nurture and care, his child-care professionals deplore Ibrahim's lack of independence and his perceived 'service expectations'. Gulløv's paper constitutes an eloquent example of Corsín Jiménez' assertion that the person is the measure of well-being, yet it also highlights the often conflicting understandings, expectations and practices that are evoked in the name of the present and future welfare of the child.

At the other end of the life course are the elderly Keralan Muslims with whom de Jong worked. Positioning her article in the context of Benda-Beckmann's concept of social security, de Jong teases out the complex, long-term, intergenerational project of ageing well. In a context where little state and NGO support exists, the house is the central pillar on which a secure old age is premised. Building a house and becoming a house owner constitutes the most stressful phase in a man's life, but it is also essential as it is closely associated with being a family and living well, conceived as several generations of a family living together under one roof. Old age is associated with a change of the kind of support provided by parents, and although old age is seen as a time of rest, the elderly are still expected to help out. Whereas in middle age support for the family was conceived as practical and financial, in old age this has shifted towards emotional and spiritual support. Within the house, elderly women increasingly leave the day-to-day running of the household to their daughters-in-law and look after the grandchildren. Elderly men also spend more time with the grandchildren and attend to spiritual mat- ters by visiting the local mosque. The strength of de Jong's paper lies in the attention paid to the precariousness of achieving a 'good old age' and the ways in which publicly acknowledged social norms are interpreted, adapted, or ignored by individual families. This could lead to the younger generation failing to continue to support their parents once ownership of the house has been transferred, as well as instances where property is divided equally or according to the children's perceived needs, rather than as prescribed by custom. A final interesting feature of the ways in which these elderly urban Keralans secured a 'good old age' is the extent to which Muslim women have become house owners, putting them into a better economic and social position than their Hindu neighbours.

Whereas de Jong focused on a good old age as the culmination of a life well lived, the authors of the final article turn their attention to the early years of adulthood. This is an unusual article in that it makes comparison between locations, which is often implicit in anthropology, explicit by drawing on fieldwork in Brazil, Uganda, Georgia and Denmark. In the Brazilian example, the transition towards what promises to be a productive adult life has been accomplished through the close personal relationship with an inspirational teacher. In contrast, the young man at the centre of the Ugandan example finds himself excluded from both traditional and modern welfare support and struggles with the realisation that his good education is probably not sufficient to help him achieve the kind of life his late father intended to set him up for. His experience of crushed hopes and limited future prospects would have been familiar to his Georgian counterparts. Surrounded by ostentatious symbols of the wealth and welfare of the Georgian nation, but confronted in their daily lives with the state's profound incapacity to provide these goods, the potential of so-called 'brotherhoods' of young men to provide mutual self-help and support their 
members' aspirations for a positive future remains severely limited. The final vignette from Denmark highlights the precariousness of faring well through one's life in the context of one of the best-developed welfare systems in the world. Although by all accounts having successfully escaped the cycle of deprivation and abuse, the young man at the centre of this vignette remains sceptical of his current good luck, thereby illustrating the difficulties surrounding the transformation of hope into certainty. By taking a double perspective that keeps both the state and the individual in mind, Højlund et al. manage to draw out the gendered modalities and multitudinous strategies in which these young men in very different geographic and cultural locations engage in, in the hope of faring well through life.

\section{Conclusion}

In this introduction we have mapped out an approach to the study of welfare that focuses on the dynamic, temporal, aspirational and interrelated aspects of welfare. Drawing on Ingold's concept of different modes of moving along lines, we aligned well-faring with wayfaring. Like wayfaring, faring well through life is rarely a straightforward journey between known points and with predictable stops and changes in between. Rather, welfare is generated through active, continuous, longterm and co-constitutive engagement between persons and their social, cultural, economic and political environments. What constitutes success in these interactions can only be assessed with hindsight, but we emphasised the importance of hope or, in Appadurai's terms, the 'capacity to aspire', as instrumental in realising this goal. We have been careful to distinguish between well-faring and well-being, not only to stress the collective element of welfare but also to draw attention to the wider institu- tional and organizational contexts that shape the pursuit of a 'good' life and to highlight the often ephemeral, precarious and elusive quality of welfare. In their thematic diversity and scope, the four articles assembled in this special issue amply demonstrate the potential that the study of welfare - or rather of wellfaring - from an anthropological perspective can bring to the discipline and beyond.

\section{Acknowledgments}

The ideas for this issue were first developed during a panel titled 'Understanding Welfare and Well-being in a Globalised World' at the European Association of Social Anthropologists (EASA) Biennial Conference, Bristol University, Bristol, 18-21 September 2006. We would like to thank the editor of Anthropology in Action for her support of this special issue and the reviewers for their intellectual acuity and helpful suggestions. Most of all, though, we would like to thank the authors for their stimulating articles and their enduring patience.

Susanne Langer trained as a Social Anthropologist. Her research interests are in the field of health and illness, death and dying, personhood, technologies and qualitative research. She is coauthor of Understanding Suicide: A Sociological Autopsy (Palgrave Macmillan). E-mail: s.langer@liverpool.ac.uk

Susanne Højlund is an associate professor in Anthropology at the Institute of Culture and Society, Aarhus University, Denmark. She has undertaken several studies involving fieldwork in Danish children's institutions and published books and papers about childhood, welfare, social identity, hominess, institutionalisation and methodology. E-mail: etnosh@hum.au.dk 


\section{References}

Appadurai, A. (2004), 'The Capacity to Aspire', in Cultural and Public Action, (ed.) V. Rao and M. Walton (Stanford: Stanford University Press), 59-84.

Benda-Beckmann, F. von and K. von BendaBeckmann, E. Casino, F. Hirtz, G. Woodman, and H. Zacher. (ed.) (1988), Between Kinship and the State: Social Security and Law in Developing Countries (Dordrecht and Providence, RI: Foris).

Clarke, J. (2004), Changing Welfare, Changing States: New Directions in Social Policy (London: Sage).

Colby, B. N. (2009), 'Is a Measure of Cultural Wellbeing Possible or Desirable?', in Pursuits of Happiness: Well-being in Anthropological Perspective, (ed.) G. Mathews and C. Izquierdo (New York and Oxford: Berghahn), 45-64.

Collier, S. J. and A. Lakoff (2005), 'On Regimes of Living', in Global Assemblages: Technology, Politics, and Ethics as Anthropological Problems, (ed.) A. Ong and S. J. Collier (Malden, MA and Oxford: Blackwell Publishing), 22-39.

Corsín Jiménez, A. (2008), 'Well-being in Anthropological Balance: Remarks on Proportionality as Political Imagination', in Culture and Wellbeing: Anthropological Approaches to Freedom and Political Ethics, (ed.) A. Corsín Jiménez (London: Pluto), 180-197.

Edgar, I. R. and A. Russell (1998) (eds.), The Anthropology of Welfare (London: Routledge).
Esping-Andersen, G. (1990), The Three Worlds of Welfare Capitalism (Cambridge: Polity).

Forskingsrådet for Kultur and Kommunication (2007), 'Kultur og Sundhed. Humanistisk Forskning i Krop, Sundhed og Sygdom', Temahxfte no. 9 (N.p.: FKK).

Ingold, T. (2007), Lines: A Brief History (London: Routledge).

James, W. (2008), ‘Well-being: In Whose Opinion, and Who Pays?', in Culture and Well-being: Anthropological Approaches to Freedom and Political Ethics, (ed.) A. Corsín Jiménez (London: Pluto), 69-79.

Mathews, G. and C. Izquierdo (eds.) (2009), Pursuits of Happiness: Well-being in Anthropological Perspective (New York and Oxford: Berghahn).

Read, R. and T. Thelen (2007), 'Introduction: Social Security and Care after Socialism: Reconfigurations of Public and Private', Focaal: European Journal of Anthropology 50: 3-18. doi: 10.3167/ foc.2007.500102.

Sointu, E. (2005), 'The Rise of an Ideal: Tracing Changing Discourses of Wellbeing', The Sociological Review 53: 255-274. doi: 10.1111/j.1467954X.2005.00513.X

Thin, N. (2009), 'Why Anthropology Can Ill Afford to Ignore Well-being', in Pursuits of Happiness: Well-being in Anthropological Perspective, (ed.) G. Mathews and C. Izquierdo (New York and Oxford: Berghahn), 23-44. 